ANNEX 1 (doi: 10.4401/ag-6757)

\section{PASSIVE DEGASSING AT NYIRAGONGO (D.R. CONGO) AND ETNA (ITALY) VOLCANOES.}

Calabrese, S., et al.

\section{A.1. SAMPLING AND ANALYTICAL METHODS}

\section{Volcanic emissions}

The technique for the assessment of the metal output from volcanoes was based on direct (inplume) collection of the plume on filter substrates. Gas and aerosols in the volcanic plume have been sampled from the rims of the active craters. Sampling was performed by pumping plume air (a mixture of gases and aerosol) for about two hours through an untreated Whatman filter placed inside a Teflon filter holder (URG-2000-30FG). This allowed solid and liquid particles to be trapped on the filter surface for later determination. Acid gases $\left(\mathrm{SO}_{2}, \mathrm{HCl}\right.$, and $\left.\mathrm{HF}\right)$ were simultaneously collected trough three base-treated filters in series ("filter packs"), previously impregnated with $1 \mathrm{~N} \mathrm{NaOH}$. Portable battery-powered pumps were equipped with flow meters to assure a constant flow rate and to measure the volume of collected air (flow rate: 41 min $^{-1}$ for filter-packs and $201 \mathrm{~min}^{-1}$ for aerosols). After sampling, filters were sealed in pre-washed plastic bags and stored in a refrigerator until analysis. Acid species were extracted from the filters by leaching with double-distilled water and $\mathrm{H}_{2} \mathrm{O}_{2}$, and the solution was analysed for $\mathrm{Cl}^{-}$and $\mathrm{SO}_{4}{ }^{2-}$ by ionic chromatography and for $\mathrm{F}^{-}$by ion selective electrode. The concentrations of metals in the collected aerosols were measured by Inductively-Coupled Plasma Mass and Optical Emission Spectrometry (ICP-MS - Agilent 7500ce and ICP-OES - Jobin Yvon Ultima2) after total digestion of the filters. The particles trapped on filters were totally dissolved in a mixture of strong ultrapure acids $\left(\mathrm{HNO}_{3}, \mathrm{HF}, \mathrm{HClO}_{4}-3: 1: 1\right)$ in a microwave oven. The absolute concentrations were corrected for filter blanks. All determinations were performed by the external standard calibration method, using ${ }^{115} \mathrm{In}$ as internal standards to correct instrumental drift; analytical errors ranged between 5 and $30 \%$ for the analysed elements.

\section{Bulk deposition}

The rain gauges used were bulk collectors which remained open during the whole sampling period, thus receiving both wet and dry deposition. They were composed of a funnel and a polypropylene (PP) bottle. The funnel (Büchner type, Ø 240mm) can be separated in two pieces for easy and total cleaning. A sheet of filter paper (DP-400-240 - basis weight: $80 \pm 3 \mathrm{~g} \mathrm{~m}^{-2}$; thickness: $0.180-0.190 \mathrm{~mm}$; retention of particles: $35-40 \mu \mathrm{m}$ ) was put inside the funnel, and a HDPE disc was inserted between the filter paper and the perforated Büchner plate to avoid clogging of the holes. The filter-system (perforated plate, HDPE disc and filter paper) excluded a prolonged interaction between sampled rainwater and coarse particulate, and minimized evaporation. All the equipment was washed with a $2 \%$ nitric acid (Merck Suprapur) solution, and then rinsed several times with de-ionized (MilliQ) water, dried under hood, packed in double clean plastic bags, and zipped until exposure in the field. Disposable plastic gloves were used whenever working with samples and sampling equipment. At the end of the sampling period, the sampling bottle was capped and transported in the laboratory for analysis.

All water samples were analysed for 38 elements at INGV-Pa. Ion chromatography was used for the determination of both major anions $\left(\mathrm{F}^{-}, \mathrm{Cl}^{-}, \mathrm{SO}_{4}{ }^{2-}\right.$, $\mathrm{NO}_{3}{ }^{-}$, and $\mathrm{Br}-$ ) and major cations $\left(\mathrm{Na}^{+}, \mathrm{K}^{+}, \mathrm{Mg}^{2+}\right.$, and $\mathrm{Ca}^{2+}$ ), using a Dionex ion chromatograph ICS1100 with suppressor and conductivity detector. Anions were analysed with an AS14A column and $1 \mathrm{mM}$ sodium bicarbonate $+8 \mathrm{mM}$ sodium carbonate solution as eluent (flow rate $1.1 \mathrm{ml} / \mathrm{min}$ ), while 
cations were analysed with a CS12A column and a $20 \mathrm{mM}$ methanesulphonic acid solution as eluent (flow rate $1.2 \mathrm{ml} / \mathrm{min}$ ). With a $25 \mu \mathrm{l}$ introduction system, the detection limits $(\mu \mathrm{eq} / \mathrm{l})$ were 0.1 for $\mathrm{Br}^{-}$, 0.2 for $\mathrm{F}^{-}, 0.3$ for $\mathrm{NO}_{3}{ }^{-}, \mathrm{Ca}^{2+}, 0.4$ for $\mathrm{Cl}^{-}, \mathrm{SO}_{4}{ }^{2-}$ and $\mathrm{Mg}^{2+}, 0.5 \mathrm{Na}^{+}$, and $\mathrm{K}^{+}$, with precision $\leq 3 \%$. Calibration curves were built using 6 calibration levels and accuracy was checked by analysing certified solutions (Ontario-99 and Lethbridge-03). Silica concentrations were as measured by using a UV-visible spectrophotometer (detection limits 0.03 $\left.\mathrm{mg}^{1-1}\right)$. Trace elements were analysed by ICP-MS (Agilent 7500ce).

The quality assurance and quality control (QA/QC) procedures included: field and analytical blanks, cleaning procedures, field and inter-laboratory comparison. The analytical precision of trace element determinations was checked by analysis of two Certified Reference Material (CRM) specific for analysis of trace elements in fresh water (SLRS-4 and 1643-e). The deviation between certified and measured values ranged from 0.5 and $27 \%$.

\section{Vegetation}

Leaves of Senecio species were had picked using disposable gloves from at least five randomly chosen plants at each sampling site. The leaves were packed into paper containers, transported to the laboratory, oven-dried at $40^{\circ} \mathrm{C}$ for $48 \mathrm{~h}$, and completely powdered by planetary ball mills. Agate jars and disposable gloves were used to avoid metal contamination. An aliquot of the powder was dried at $40^{\circ} \mathrm{C}$ for 24 hours, and about $250 \mathrm{mg}$ of each homogenised sample were mineralised for $60 \mathrm{~min}$ by Closed Vessel Acid Digestion in a microwave oven (CEM MARS Xpress) using Teflon vessels with $3 \mathrm{ml}$ concentrated $\mathrm{HNO}_{3}$ (ultrapure grade $65 \%$ ), $2 \mathrm{ml} \mathrm{H}_{2} \mathrm{O}_{2}$ (ultrapure 39\%) and $5 \mathrm{ml} \mathrm{milliQ-}$ water. Control samples were added to each batch of samples as follows: at least four certificate reference materials, three replicates of one random sample and one method blank (acid solution without any powder). Digestates were further diluted with milliQ-water up to a total volume of $50 \mathrm{ml}$ and analysed by ICP-MS (Agilent 7500-ce) and ICP-OES (Jobin Yvon Ultima2) spectrometers. Multi-element calibration standards were prepared freshly by dilution from certified stock solutions, and standard solutions of ultrapure quality, and milliQ-water. Matrix induced signal suppressions and instrumental drift were corrected by internal standardization ( $\mathrm{Rh}$, In and Re). Method blank values were subtracted from the raw concentrations of all samples. 